Title: "Discussion on "Script for the playing of a 7" phonograph record prepared for readthrough' between Sarah Jones and Martin Westwood"

Authors: Sarah Jones, Martin Westwood

\begin{abstract}
This article records an email discussion between Martin Westwood and Sarah Jones the protagonist for which was the reading aloud of the "Script for the playing of a 7" phonograph record prepared for readthrough" at the symposium Headstone to Hard Drive 2 on $7^{\text {th }}$ February 2015 at Central Saint Martins, London. The script that was read from is printed here.

In identifying the potential of documentation, not in the realm of representation but as interception, the discussion posits how the protocols of a script maybe expanded as both a record and a proposition. It goes on to consider how the form of the riddle and riddling inhabits a doublemindedness of oral and aural register alongside the graphic, creating a doubled sense of hearing and seeing.
\end{abstract}

Keywords: scripts, Anglo-Saxon riddles, Bernhard Siegert, documentation, Earle Brown, Gertrude Stein

\title{
Martin Westwood:
}

Email address:m.westwood@csm.arts.ac.uk 
Martin: To fill in the background of this dialogue: we had a public conversation on February $7^{\text {th }}$ 2015 at 'Headstone to Hard Drive 2' at Central Saint Martins, this was shortly after you had performed 'Script for the playing of a 7" phonograph record...' The script is printed here in the Journal though there was never any visual documentation produced of that performance. This lack of a visual record reflects not only your approach to documentation but might it also be seen as indicating a central concern of your work. Could you say something about the importance of inscription, recording, the issue of documentation and the lack of a photographic visual record?

Sarah: Last night I went to a performance of Earle Brown's Chef d'Orchestre, that's the way I am citing it, it is a musical composition in which Chef d'Orchestre made by Alexander Calder plays a part or should I say several parts. I witnessed it being still, being mobile, being a musical instrument for others, being a conductor of sound of its own and of four percussionists each stood in an island of umpteen percussion instruments. For periods during the performance, these percussionists followed each other stroking and hammering wood and metal, they deserted their islands, they played with the mobile ringing its tones, it played with them and as it played with them it sometimes got away. They prodded it; and rotating, it span, taken by its own momentum. When it caught the side of a beater, it was not a ringing sound, it was a clank when one of its gently swinging metal plates snagged on its axis slowing the momentum before freeing itself. The percussionists returned to their islands from where they watched the rotating swinging plates, listening, following the movement as they raised and brought down their hard and soft beaters.

In documentation, what constitutes the document and the role it takes is a live question or better still it is an exchange between the document and the documented. This isn't limited by the to and fro of two items but maybe a recursive process; it's the 'Script for the playing of a 7" phonograph record prepared for readthrough' you see printed in this journal, the reading of it at the symposium, the performance of 'the playing of a 7" phonograph record' described in the script, the transparent gold 7" phonograph record being played, the graphic score of the sounds you hear when the record is played. That graphic score is an overlarge sheet of wafer thin paper transected by horizontal stripes of flesh face paint and yellow tape and scattered biro drawn stick figures; its title is 'score for it, what, ur', and it is difficult to handle. What is made is from what is found in the feedback loop, like it . Documentation is and is for interpretation; the what of it is evasive, akin to the riddle in that it also obscures what it names. It has in it the potential to prompt a way of seeing, of listening, of touching the imagination; how the beholder makes it up. Publishing the 'Script for the playing of a 7" phonograph record prepared for readthrough" here is an attempt to balance aspects of the visual and the aural. Some of the materials and methods of its reproduction already exist such as the qualities of the page this is printed on and methods of its reproductions, the weight of a page the resolution of a screen will bring their weight to bear on what it is. I don't know them as I write this but you will know them as you read it.

To go back in time, there was a moment when I decided to stop photographing my work. With a sculptural practice taking photographs of the sculptures, the things I made, was something I had felt I was supposed to do. The decision to stop was a pithy one; it came from being bored with listening to my soundtrack of moans accompanying the endless disappointment of looking at the 
photographs. At that point there was no plan for doing something in its place, just pleasure of being released from a burden. Now, I ask what I can do for the 'it' that is being, documented. What is the tone, the temperature, the weight, the texture; I can't put a complete list here because that would suggest there is a predetermined set of questions, there is not. Any question that is brought forth will have a bearing, a weight, it will hang, how it hangs.

Martin: I was not at the performance of Chef d'Orchestre but, appropriate to this conversation, I have looked at the audio-visual documentation. In the light of your statement that "documentation is...for interpretation" would it be fair to test pushing this statement towards: "documentation can be considered as a technical and material interception'? In the Earle Brown composition there is an expansion of the sculpture's peripheries, re-scripting it as an orchestral conductor and as acoustic instrument. It is intercepted as a sculpture emphasising that formats and protocols are porous unless their borders are effectively patrolled, that there are no mediums but always, and only, media, that there is no 'it' before the event of re-performance or re-scripting, only a motion of reconstitution providing 'it' with stability. This moves the document away from being considered as a form of representation and towards its capacity to distort received formats or protocol. This is why I am wondering about the term interception as opposed to interpretation. Interpretation maintains the capacity for representation, even if under technical anamorphosis, whilst interception is not a distorted channel but as Bernhard Siegert recently wrote, in the context of discussing Michel Serres' model of communication, prioritises that the "origin lies with the pirate rather than with the merchant, with the highwayman rather than with the highway". Significance arises in the expansion of noise rather than in communication.

Sarah: I am not sure about all documentation, maybe. I like the suggestion of an interception; my first response, that it has dark overtones of an action stopping something reaching its intended or desired destination, is tempered by a question of where does that thing go then, could it be held in suspension or does it become diverted to a new destination. It offers something that goes along as an alternative to documentation as representation. I'll trip up here because I am thinking about how and why to represent something all the time but whilst I'm thinking this I'm also busy avoiding that thing being pinned down, that is to say being reduced by representation. Between this thought and that, 'that' being your quote from Bernhard Siegert, I've travelled towards Marcel Duchamp's 3 Standard Stoppages a wry and sexy work "casting pataphysical doubt on the concept of a straight edge as being the shortest route from one point to another" ${ }^{\prime \prime}$. They add noise. They are a record. They are a proposition. They are an interception. As is a script?

Martin: 'Script for the playing of a 7" phonograph record...' has had more than one manifestation, is that right? Could you describe something of the journey, or biography, that the script and performance have taken (either independently as forms or together as accomplices) and the script's initiation within the Samuel French script format?

Sarah: Samuel French is a publisher of plays and musicals and a theatre bookshop. When I first started looking at their plays I recognised something of a protocol for recording the performance of a play on a given date in a given location whilst also being a proposition for its future performance. This protocol identifies, amongst other things: the cast, concrete constructions such as lighting and effects plot descriptors, stage layout and props lists as well as the directions and dialogue. Many of 
these items would be absent from a literary publication that intends for a play to be read as if it were a dialogical novel.

The 'Script for the playing of a 7" phonograph record...' follows the Samuel French format and their protocol for identifying parts of a play except it does not record a dialogue, though its reading can suggest one. There are two ways to think about staging it, one is as a play, performing the actions with the props in a set and as the script contains no prescribed dialogue it maybe the only words heard come from playing the 7" phonograph record, the second is as a readthrough, reading aloud all the words printed in the script. The relative temporal positions are not fixed and in this way they differ from a conventional understanding of the readthrough as a part of a rehearsal process for learning/developing dialogue in a play usually without the set, other object props or costume etc. in the lead up to a play being performed.

What you see printed here is the version of the script prepared for readthrough by two people. At 'Headstone to Hard Drive 2', reading from left to right the two readers alternated who spoke the words, in accordance with the colour change in the text (reader A: words printed in light sky blue and reader B: words in pale burnt umber). The script was read aloud twice, in its second iteration as each was reading the other was required to look at her counterpart, regard her as if listening, visually approximating a dialogue. This was not the only thing being approximated in its performance, the staging of the readthrough also seeks to approximate, in the look of the readers and the backdrop curtain, characteristics described in the script under the heading Tones Plot. This plot descriptor being an invention added to the Samuel French format, quotes observations made about the materials of the artwork on the occasion of the playing of a 7" phonograph record itself. The Incidents Plot is similarly an invention pertaining to actions on the same occasion. There was script before this one that did not have the Tones Plot or the Incidents Plot or some of the stage directions, because they had not happened yet. Every performance rewrites its script. For all this describing, it does not directly address the 7" record, is it a titular character which is read aloud in the script? There is something to be said for oblique references. Though it might not be in words.

Martin: "Every performance rewrites its script", it sounds like your script might be similar to a depository for the performances. A place where the previously unscripted is sedimented as it is made discrete and inscribable within the script. So the script is like a sort of necropolis of animation or contingent performances which each require a new Plot-line; a Tones or Incidents Plot. It appears there is a dialogue at the centre of your notion of script between prescription and description. There seems to be an important idea of motion here or transposition from the prescribed intentional script towards its occasions. In such a way it also seems to follow some Xeno-like paradox in which a process of division and accretion permanently delays any arrival. I'm tempted to consider that the destination is a paradoxical movement away from the intentional script towards a script that has become observable and externalised through its self-referentiality. You've written of the significance of riddles before, are they relevant here?

Sarah: Can I ask you to flesh this out a little more, as it stands the depository's relationship to death in the necropolis is bearing down on the script as an end point, how might it also be working as 
animation? I am wondering if it is connected to the riddle in your question and if to go back to the idea of being approximately something, being a matter or resemblance of which Gertrude Stein says

A resemblance is always a pleasurable sensation and so resemblance is almost always there. That is not the business so to speak of the oil painting, that is just a pleasant human weakness. Anybody and so almost everybody pleasantly likes anything that resembles anything or any one. Then there is another thing another pleasant human weakness. There is another thing about an oil painting. It makes you see something to which it is resembling makes you see the thing in the way it the oil painting resembles it. And that too and that again is a pleasant thing. But then really and this everybody knows, very soon anybody that is everybody really forgets about this resemblance. They naturally do do so because things change at least they seem so to do or any way they look as if they did change that is they look different and so the resemblance of the oil painting that is to anybody that is to anything is only a thing that has become historical. ${ }^{i i}$

Martin: Perhaps 'depot' is a better word than depository, it at least implies a continuing transport and the script is both the skeletal frame of what has been occasioned in performances and the possibility of their re-staging; in-bound and out-bound journeys. I understand the script begins without description of any actual topography and it develops by incorporating its temporal displacements (ambient factors of its performance written as new plot devices) in an accretive manner. A process that ultimately is imaginable as over-shadowing the script with its occasions, just as those occasions become the script through accretion. I suppose I am trying to get inside this dynamic, this economy between the animate performance and the inanimate script and acknowledge that if there is a gap between the two then in/animate is not an adequate polarity. But there may not be an adequate, or approximate, polarity. Instead, perhaps the gap might be where the riddle or the paradox of a necropolis of the animate exists?

Sarah: $\mathrm{mmm}$ and in its accretion, this dynamic of animate/inanimate is as a movement; a hovering that may be a frustration. I've contemplated before the pleasure of Anglo-Saxon riddles, and listening to your questions I realise there's a dimension to them that I'd previously not fully recognised in the operation of the riddle's provision for a ludic approach to the biography of an object. The riddle invites us to get to know a thing, to make multiple approaches to that thing from different angles. Introducing itself, the riddle positions us at a threshold of what it is. Speaking in the first-person, it is the verbal identity of an object speaking on the occasion of its manufacture and revealing important details about its social and imaginative identities. It may tell us its material properties, the process of its manufacture, it's setting and also the time in which it exists, its use and its effects:

"Edison patented me. Named Sarah Jones, I am spun. No black opaque unusually I am gold and transparent, I say itit"

There are dozens of Anglo-Saxon riddles preserved in the Book of Exeter ${ }^{\mathrm{iv}}$; I find a marvelous pleasure in reading the text and picturing their poetry. Their written preservation is remarkable because they are of an oral tradition, and it is this your questioning prompts: that knowing of their 
oral nature is not sufficient I need to be reminded or remind myself continuously that they are of this and remembering this to remember the speaker and the materials and the voice of that speaker, that they are an imaginative identity in the biography of the object too. To forget this is to conjure an endpoint.

Martin: I see the riddle is a genre that presents data and qualia playfully searching to be cast as information, or alternatively acting as a ludic ambush, trap, pitfall. Also I am fascinated by a genre transposing or re-iterating itself in registers other than that in which it is initiated. A situation in which considering the genre generates more of itself as the genre becomes encoded across strata such as between the oral and the written. I wonder if figuratively the riddle's genre re-appears in the border between the phonetic and graphic registers and that this zone in order not to become a moment of total discontinuity becomes occupied by the reminder you talk about. That the reminder is serving to create and patch together two registers. Though it has other effects as well. In this case the riddle creates awareness of the oral and aural register alongside the graphic, written register creating a doubled sense of hearing. We see written words, and as we read with our eyes we stimulate a virtual hearing, simultaneously we are reminded to hear them as spoken and virtually construct an ear that hears (or heard) a mouth speak. In both situations the ear is outside itself, in the eye of the reader or in the mouth of another. The reminder serves to situate the one who is reminded at that point the spoken and heard is transposed into the graphic and seen/read, and vice-versa. It is not so easy to think these two registers simultaneously; there seems a trap or pitfall. That the reminder has created a double-mindedness. Is this in itself a figurative transposition of the riddle across two technical registers?

Sarah: Yes, it is. I'd say that you are getting to something here, in the difficulty of holding these two registers simultaneously, resulting in something mobile, and this is the riddle embodying playfulness and the puzzling of a thing.

On wondering - perhaps some of this riddling is obscured when it is consigned to the clue of a crossword, merely as something to solve. What remains is play and direction as the cruciverbalist approaches, backs up and re-approaches time and again to see that thing from different angles. But for whatever else it is, the riddle is an image text; as I am reading I am listening to the thing describing itself in visual terms and I am picturing what it is describing and in the picturing of what it is describing is - is itself - oh heck it is willfully playful. And here I am being reminded, again, as it presents its own stumbling block (this trap or pitfall of double-mindedness) and it does this by stealth and by being in plain sight - it is cunning.

Martin: The reminder inserts itself between the mindful and the forgetful. And a triangulation is produced between the mouth, eye and ear, where the virtual ear occupies this place of insertion between the reading eye and the speaking mouth. This ear is the reminder to "remember it was once heard" and in the wake of this reminder the phantom ear of the reader's eye appears. This very real ear is like an annoying intermediary - virtual, phantom.

Sarah: It has a wry humour: "wry" - double you are why 
${ }^{\mathrm{i}}$ Siegert, Bernhard. 2014. 'Cultural Techniques: Grids, Filters, Doors, and Other Articulations of the Real'. 21. (New York: Fordham University Press,).

${ }^{\text {ii }}$ Anne d'Harnoncourt and Kynaston McShine, eds. 1973. Marcel Duchamp. 273-4. Exhibition catalogue, Philadelphia Museum of Art.

${ }^{\text {iii }}$ Stein, Gertrude. 1935. Lectures in America, 79-80. (London: Virago Press, 1988).

iv The dates of the Riddles are unknown but are of an oral tradition in a time when the power of an object was given credence outside of human agency. The Book of Exeter is an anthology of Anglo Saxon poetry produced some time before 1072 when it is known to have been donated to the library of Exeter Cathedral. 